\section{OPTIMISED FLUORIDE DELIVERY}

Farlier this vear research by the makers of Pronamel found that $83.5 \%$ of dentists

saw acid wear amongst their patients on a weekly basis.' Experts believe that

consuming four or more acidic foods and drinks a day can increase the risk of

acid wear ${ }^{2-4}$ - dietary and behavioural advice is key to reducing patients' risk.

In addition to dietary and behavioural advice to your patients, you can also

recommend a specialist toothpaste. Pronamel toothpaste has been designed

for optimised fluoride delivery in a non-abrasive, pH-neutral formulation, ${ }^{5}$ and it's

proven to help protect against the effects of acid wear. ${ }^{6.8}$

When giving advice to patients showing signs of or at risk from acid wear,

recommend Pronamel

GSK Data on File, 2013.

Murakami $\mathrm{C}$ et al. Risk indicators for erosive tooth wear in Brazilian preschool children. Caries Res 2011:45: 121-129.

3. Lussi A et al. The role of diet in the aetiology of dental erosion. Caries Res 2004; 38 (Suppl 1): 34-44.

Dugmore C R, Rock W P.A multifactorial analysis of factors associated with dental erosion. Br Dent J 2004; 196: 283-286

Layer T M. Formulation considerations for developing toothpastes suitable for those at risk from erosive tooth wear. J Clin Dent 2009; 20 (Spec Iss): 199-202

6. Hara AT et al. Influence of fluoride availability of dentifrices on eroded enamel remineralization in situ. Caries Res 2009; 43: 57-63.

Fowler $\mathrm{C}$ et al. In vitro microhardness studies on a new anti-erosion desensitizing toothpaste. J Clin Dent 2006; 17 (Spec Iss): 100-105

Fowler C E et al. Fluoride penetration from toothpastes into incipient enamel erosive lesions investigated using dynamic secondary ion mass spectrometry. J Clin Dent 2009: 20 (Spec Iss): 186-191
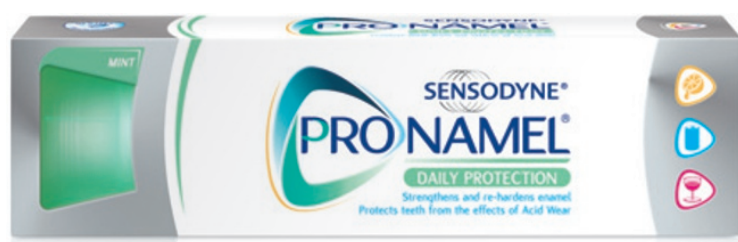

NEW AQUAFRESH LAUNCHES FOR 2013

As the number one

kids' oral care brand

Aquafresh understands

the importance of good

oral care habits from an

early age. As well as an

oral care range suitable

for every stage in a child's

development, engaging

packaging designs

and age appropriate

toothpaste formulations,

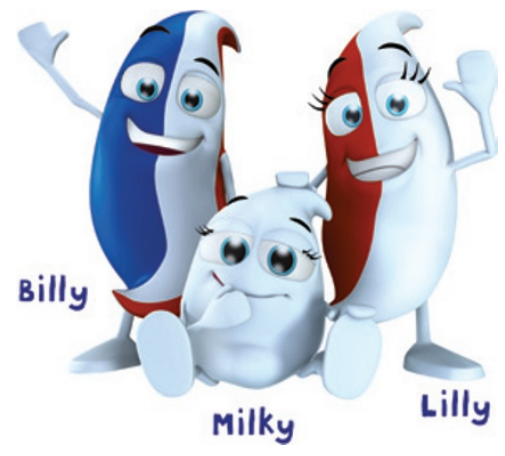

the brand supports the education of younger patients and their carers through

the provision of Aquafresh Kids Motivation Packs to dental surgeries. Now

Aquafresh is expanding this initiative to encourage better brushing in the

community, as well as in practice, with the 'Better Brushing Programme'.

The 'Better Brushing Programme' is designed to support the fantastic work

dental professionals are doing through the provision of educational materials and product samples within their local community

GlaxoSmithKline Consumer Healthcare has also refreshed the products within the Aquafresh kids range. The Aquafresh Kids toothpaste range is staged by age to contain the appropriate level of fluoride in line with the Department of Health guidelines ${ }^{\top}$ and a mint taste profile which is designed to help children progress to the flavour of adult toothpaste. Aquafresh My Big Teeth Mouthwash is for children age $6+$ and is available in two flavours. Aquafresh children's toothbrushes feature new packaging and appealing designs. The brand is also launching a new

teether for babies.

www.gsk-dentalprofessionals.co.uk.

Nielsen data Kids Oral Care Total Coverage value sales. 12 weeks to WE 30.03.13.

Department of Health (UK), NHS. Delivering better oral health - an evidencebased toolkit for prevention, 2nd ed. 2009.

\section{PARTIAL DENTURE STARTER KIT}

The Poligrip starter kit has been hugely successful - dental professionals say the kit really helps when preparing patients for life with dentures. Now Poligrip is building on this success with the launch of the Partial Denture Starter Kit.

The Partial Denture Starter Kit features all the advice and materials which have made the original starter kit so popular - all updated and revamped for the specific needs of partial denture wearers. Partial dentures can have implications for the health of the remaining dentition' and your patients depend on your help to maintain their oral health once their partial dentures are fitted.

Since nothing can replace the advice of a dental professional, the kits contain materials to help you provide both functional and emotional support to your patients. The kits also contain materials to give directly to your patients, including a booklet giving guidance and advice, and samples of the two new Poligrip for Partials products: Seal \& Protect denture fixative cream, and Clean \& Protect denture cleansing tablets.

Poligrip Clean \& Protect denture cleansing tablets kill $99.9 \%$ of organisms on dentures. ${ }^{2}$ The tablets are non-abrasive ${ }^{3}$ to clean without scratching, and non-corrosive ${ }^{4}$ to protect metal clasps. Poligrip Seal \& Protect denture fixative cream helps stabilise partial dentures to reduce movement on the gum and against neighbouring teeth, and helps seal out food particles to reduce gum irritation.

Poligrip Partial Denture Starter Kits can be requested at www. gsk-dentalprofessionals.co.uk or by calling 08456000441 . Request your FREE kit today, and help prepare your partial patients for dentures.

Davenport J C, Basker R M, Heath J R, Ralph J P. Glantz P O. The removable partial denture equation. Br Dent J 2000; 189: 414-424

GSK Data on File, Micro study, 2012

GSK Data on File, Fernandez et al. 2006

GSK Data on File, Alliance Corrosivity Report, 2012.

GSK Data on File, Murphy et al. 2012.

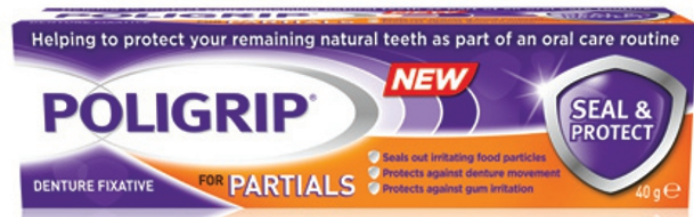

THE TALKING POINT OF THE YEAR

As Talking Points in Dentistry celebrated its 28th year of excellence in learning, the popular lecture series attracted over 3,000 dental professionals to ten venues across the UK.

This year saw a new format for the series, which combined a topical lecture with a follow up panel debate session, allowing the audience to have their say. The panel was locally sourced, allowing a regional input to the events from all members of the dental practice team. Dr Anoop Maini delivered a presentation entilled, 'Is successful dentistry more than just a beautiful smile?" The follow up panel discussion then spurred conversation around topics such as direct access and the role of the treatment coordinator.

Talking Points in Dentistry is GSK's flagship dental event. If you missed out on the event, then further information about the lecture and videos are available to access at umw.gsk-dentalprofessionals.co.uk.

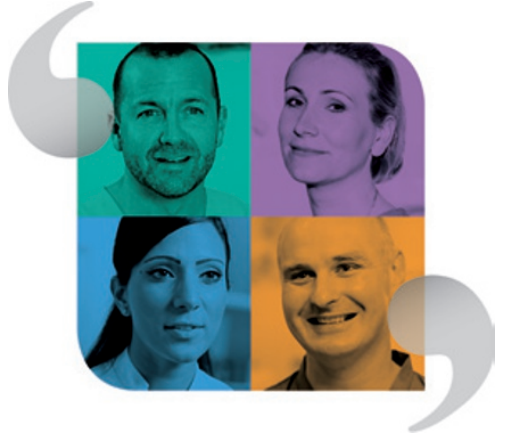

